\title{
Observed and modelled ice temperature and velocity along the main flowline of East Rongbuk Glacier, Qomolangma (Mount Everest), Himalaya
}

\author{
Tong ZHANG, ${ }^{1,2}$ Cunde XIAO, ${ }^{1,3}$ William COLGAN, ${ }^{4,5}$ Xiang QIN, ${ }^{1}$ Wentao DU, ${ }^{1}$ \\ Weijun SUN, ${ }^{1,2}$ Yushuo LIU, ${ }^{1}$ Minghu DING, ${ }^{1,3}$ \\ ${ }^{1}$ State Key Laboratory of Cryospheric Sciences, Cold and Arid Regions Environmental and Engineering Research Institute, \\ Chinese Academy of Sciences, Lanzhou, China \\ ${ }^{2}$ University of Chinese Academy of Sciences, Beijing, China \\ ${ }^{3}$ Institute of Climate System, Chinese Academy of Meteorological Sciences, Beijing, China \\ E-mail: cdxiao@Izb.ac.cn \\ ${ }^{4}$ Cooperative Institute for Research in Environmental Sciences (CIRES), University of Colorado at Boulder, Boulder, CO, USA \\ ${ }^{5}$ Geological Survey of Denmark and Greenland, Copenhagen, Denmark
}

\begin{abstract}
Knowledge of present-day ice temperature and velocity is important in order to determine how fast a glacier will respond to present and future climate change. We apply a two-dimensional higher-order thermomechanical flowband model to simulate present-day ice temperature and velocity along the main flowline of East Rongbuk Glacier, Qomolangma (Mount Everest), Himalaya. We use recent (2005-11) observational data to validate the numerical model. Modelled and observed ice surface velocities exhibit good agreement. Modelled ice temperatures agree well with observed values in two shallow boreholes that are $\sim 18 \mathrm{~m}$ deep. The model suggests that the ablation zone of East Rongbuk Glacier, $\mathrm{km} 4$ to $\mathrm{km} 10$ from the glacier head, is underlain by temperate ice.
\end{abstract}

\section{INTRODUCTION}

As Himalayan glaciers represent the largest ice volume in the world outside the Arctic and Antarctic, and are an important freshwater resource for approximately 750 million people (Barnett and others, 2005; Immerzeel and others, 2010), understanding how glaciers will change in the Himalayan region is a pressing question. Anticipating future changes in the valuable freshwater resources of the Himalayan region requires a validated numerical ice flow model. Nevertheless, due to the very limited availability of glaciological in situ measurements (e.g. glacier geometry, surface mass balance, ice temperature, ice velocity), very little numerical modelling work has been done on Himalayan glaciers, and most of those studies are on the southern slope of the Himalaya (e.g. Naito and others, 2000; Adhikari and Huybrechts, 2009). The glaciers on the northern slope of the Himalayan range are different from those on the southern slope, as they experience a continental climate characterized by relatively low air temperature and humidity (LIGG, 1988). Thus, to understand the consequences of climate change for the magnitude and temporal distribution of meltwater runoff across the entire Himalayan range, practical dynamical modelling of glaciers on the northern slope of the Himalayan range is of great importance.

Qomolangma (Mount Everest), located in the middle Himalaya at $27.98^{\circ} \mathrm{N}, 86.92^{\circ} \mathrm{E}$, is the highest peak on Earth, reaching an elevation of $8844 \mathrm{~m}$ (Fig. 1). East Rongbuk Glacier (ERG) is a compound valley glacier located on the northern slope of Qomolangma with a length of $12.1 \mathrm{~km}$ in 2011 (Zhang and others, 2012) and an area of $27.3 \mathrm{~km}^{2}$ in 2008 (Ye and others, 2009). Since the first scientific expedition to Qomolangma in 1959-60, many surveys have been undertaken in fields such as meteorology, glaciology, hydrology and geology (e.g. Gao, 1980; Kang and others,
2001; Hou and others, 2007; Liu, 2010). However, very little research on ice temperature and velocity, the most important state variables required for a glacier model, has been undertaken in the Qomolangma region.

In May 1960, a shallow borehole was drilled at $5400 \mathrm{~m}$ a.s.I. on Rongbuk Glacier, $\sim 1 \mathrm{~km}$ west of ERG, and the ice temperature at $10 \mathrm{~m}$ depth was measured as $-2.1{ }^{\circ} \mathrm{C}$ (TSECAS, 1975). Ice temperature was also measured in a deep crevasse at $6325 \mathrm{~m}$ a.s.I. on ERG in April 1968, which suggested a value of $-12.2^{\circ} \mathrm{C}$ at $25.5 \mathrm{~m}$ depth (TSECAS, 1975). Ice temperature measurements were also obtained at discrete depths in a $108.8 \mathrm{~m}$ borehole drilled to bedrock at $6518 \mathrm{~m}$ a.s.l. on ERG in September/October 2002. These borehole ice temperatures were $-9.6^{\circ} \mathrm{C}$ at $20 \mathrm{~m}$ depth and $-8.9^{\circ} \mathrm{C}$ at $108.8 \mathrm{~m}$ depth (Hou and others, 2007; $\mathrm{Xu}$ and others, 2009). Despite these few in situ measurements indicating ice temperatures well below the pressure-melting point, which is approximately $-0.09^{\circ} \mathrm{C}$ at $100 \mathrm{~m}$ ice depth, Huang (1999) speculated that large valley glaciers in the Qomolangma region likely sustained temperate ice zones (TIZ) in the basal ice of their ablation zones.

Prior to 2005, ice velocity measurements on ERG had only been made on two cross sections at 5600 and $5900 \mathrm{~m}$ a.s.l. over a 4 month period in summer during the 1959-60 expedition. These observations suggested that ice velocity varied from several metres to tens of metres per year (TSECAS, 1975). Most existing in situ measurements of ERG surface velocity were obtained during 2005-11.

Due to logistic difficulties, it is hard to drill and instrument boreholes for the measurement of ice temperature and velocity profiles at as many locations as we would have wanted. Numerical modelling, validated against the sparse observational data, thus offers an alternate approach to derive complete distributions of englacial temperature 
and velocity. In order to develop a fully transient glacier dynamic model for projecting future changes of glacier meltwater runoff, a validated diagnostic ice flow model must first be developed. This is the primary aim of this paper.

In this paper, we use a two-dimensional (2-D) higherorder thermomechanical flowband model to study the diagnostic behaviour of ERG. We first describe the model input data (i.e. ice surface velocity, glacier geometry, surface air temperature and geothermal heat flux), and then briefly describe the numerical model that we employ. We adopt a phenomenological friction law to simulate the basal sliding in the ice flow model and use a numerical iteration scheme to determine the locations of cold-temperate transition surface (CTS) in the temperature model. Finally, we present and discuss the major findings of this research, which include the model sensitivity experiments, the simulated present-day ice temperature and velocity distribution along the main flowline (MFL) of ERG, and their comparison with available in situ observations.

\section{MODEL INPUT}

\subsection{Ice surface velocity}

Due to the difficulties of conducting fieldwork in heavily crevassed areas, in situ ice velocity data are sparse for ERG. We provide some in situ ice surface velocities for ERG, inferred from stake displacements measured between repeat stake surveys using the GPS. These in situ velocity observations include annual velocities observed between May 2007 and May 2008, summer velocities observed between April and October in 2009 and 2010, and the winter velocities observed between October 2010 and June 2011. The locations of the surveyed stakes (2007-11) along the MFL are shown in Figure 2. Over a large portion of the glacier $(\mathrm{km} 2.4-6.5$ from the glacier head), only summer velocity data exist (Fig. 3). Based on the observation that the summer velocity at $5775 \mathrm{~m}$ a.s.I. ( $\mathrm{km} \mathrm{9.1)} \mathrm{is} \mathrm{approximately} \mathrm{twice} \mathrm{the}$ winter velocity, we estimate mean annual velocities by multiplying summer velocities by a factor of 0.75 (Fig. 3).

\subsection{Glacier geometry}

In May 2009, a ground-penetrating radar (GPR) survey was conducted on ERG using a pulseEKKO PRO radar system with a centre frequency of $100 \mathrm{MHz}$ (Zhang and others, 2012). Both the antenna separation and step size were set to $4 \mathrm{~m}$. Since the terminus of ERG is covered by up to several metres of debris, a common-midpoint (CMP) survey was performed to calibrate radar velocity below 5600 ma.s.l. ( $\mathrm{km} \mathrm{11-12).} \mathrm{The} \mathrm{average} \mathrm{radar} \mathrm{velocity} \mathrm{inferred} \mathrm{for} \mathrm{the} \mathrm{thick}$ debris-covered region was $0.13-0.15 \mathrm{~m} \mathrm{~ns}^{-1}$ (Zhang and others, 2012), and a radar velocity of $0.168 \mathrm{mns}^{-1}$ was assumed in the clean ice zone (e.g. Bradford and others, 2009). The maximum ice thickness along the MFL of ERG is $\sim 320 \mathrm{~m}$, and the average is $\sim 190 \mathrm{~m}$.

The cross-sectional glacier shape may be described by a power law function, $z(y)=p y^{q}$, where $y$ and $z$ are the horizontal across-flow and vertical distances from the lowest point of the cross section, and $p$ and $q$ are constants. $q$ is commonly used as an index of the steepness of the valley side, while $p$ is a measure of the width of the valley floor (Svensson, 1959; Graf, 1970). For ERG, we find that $q$ varies within the range $0.7-1.3$ and $p$ has an exponential relation with $q,-\ln (p)=7.1 \times q-6.5$ (Zhang and others, 2012).

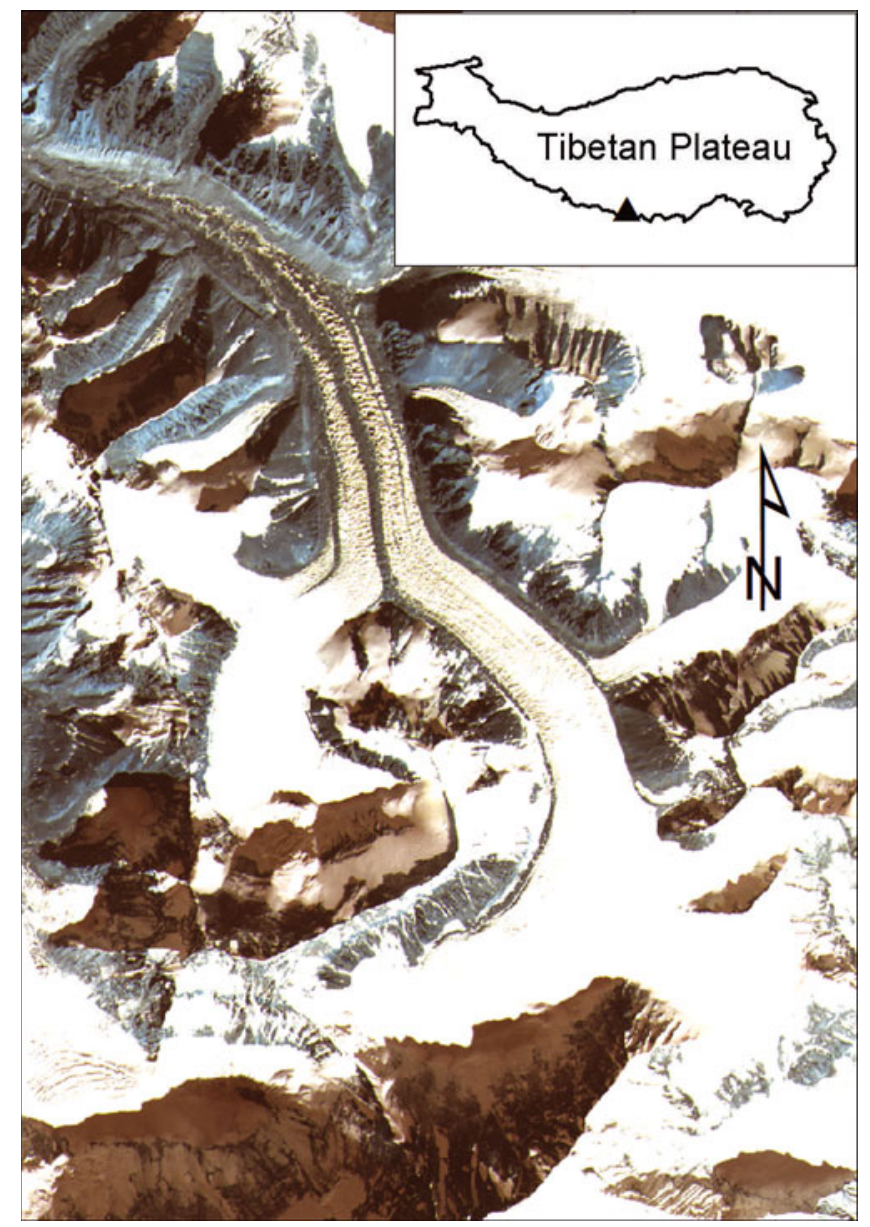

Fig. 1. Advanced Land Observing Satellite (ALOS) 2007 image of ERG. The location of ERG is shown as a triangle in the inset.

This indicates that the cross-sectional profile of ERG may be regarded as ' $\mathrm{V}$ '-type.

Few GPR survey lines overlapped with the MFL above

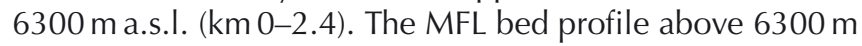
a.s.I. was therefore inferred by transposing data from nearby GPR survey lines based on the cross-sectional shape of the glacial valley perpendicular to ice flow (Zhang and others, 2012). In the elevation band between 6000 and $6300 \mathrm{~m}$ a.s.I. ( $\mathrm{km}$ 2.4-6.5), where the glacier surface is composed of large ice seracs, ice thickness was inferred by cubic interpolation of upstream and downstream observations. A central moraine ridge divides the glacier into two deeply incised adjacent channels between 5800 and 6000 m a.s.l. (km 6.58.8; Fig. 1; Zhang and others, 2012). When calculating the ice thickness and glacier width along the MFL we ignore all tributaries (Figs 2 and 4).

\subsection{Surface air temperature}

During the 2008 Olympic torch relay, several automatic weather stations, ranging in elevation from 5207 to $7028 \mathrm{~m}$ a.s.l., were installed by the Chinese Academy of Sciences at Qomolangma. A HOBO automatic weather station deployed at $5708 \mathrm{~m}$ a.s.l. ( $\mathrm{km}$ 9.8) recorded a mean annual air temperature of $-5^{\circ} \mathrm{C}$ during the $2009-11$ period. We use the average environmental lapse rate at ERG recorded by these stations, $-0.72{ }^{\circ} \mathrm{C}$ per $100 \mathrm{~m}$ rise in elevation (Yang and others, 2011), to calculate the mean annual air temperature at different elevations on ERG. 


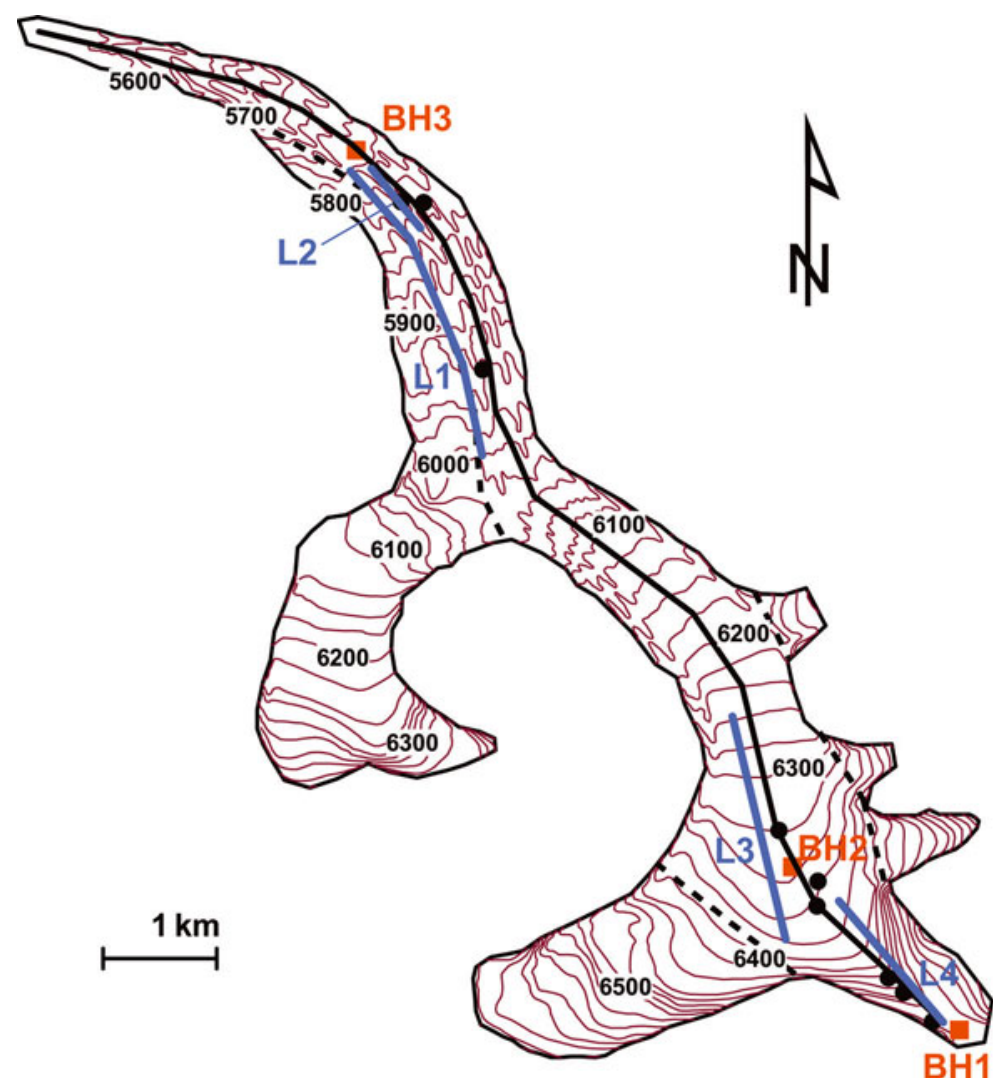

Fig. 2. Map of ERG. The contours are produced from a 1:50000 topographic map made in 1974. The black thick line and thin dotted lines denote the main flowline (MFL) and the boundaries of tributaries, respectively. Black dots denote stake sites for ice surface velocity measurements along the MFL. BH1 (6518 m a.s.I.), BH2 (6350 m a.s.I.) and BH3 (5710 m a.s.l.) denote ice boreholes (red squares). The blue lines, L1, L2, L3 and L4, are ground-penetrating radar survey lines.

\subsection{Geothermal heat flux}

The ice temperatures in a borehole drilled to bedrock near the flow divide in 2002 (BH1; Fig. 2) were $-9.6^{\circ} \mathrm{C}$ and $-8.9^{\circ} \mathrm{C}$ at depths of 20 and $108.8 \mathrm{~m}$, respectively (Hou and others, 2007; Xu and others, 2009). According to snow-pit measurements, the mean annual surface mass balance at BH1 in 2002 was $\sim 400 \mathrm{~mm} \mathrm{a}^{-1}$ (Hou and others, 2007). The drilling site was selected where there was negligible horizontal ice velocity (Hou and others, 2007; Xu and

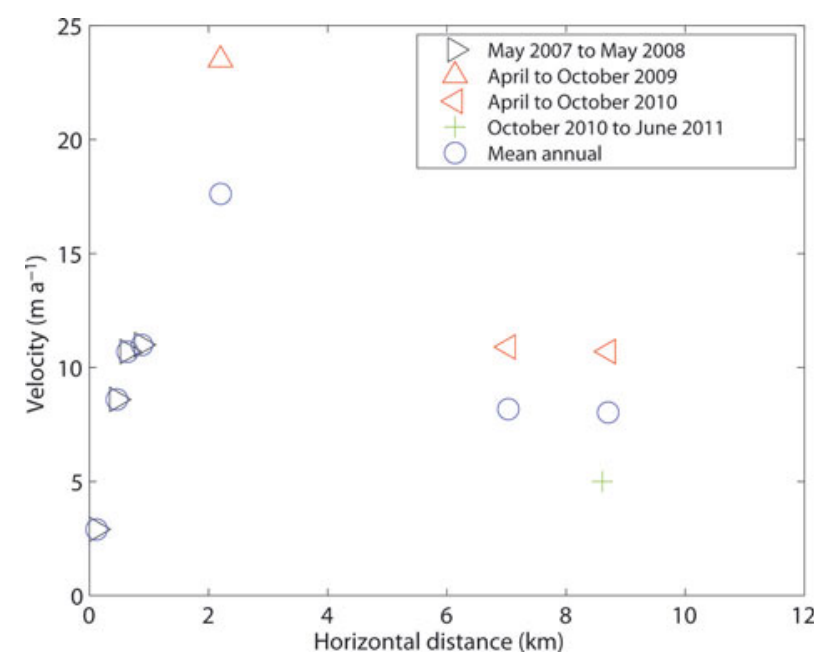

Fig. 3. In situ ice surface velocity observations along the MFL of ERG. The mean annual velocities are estimated by mutiplying the summer season velocities by 0.75 . others, 2009). Similar to the 2-D energy-balance equation described in Section 3.2 below, a one-dimensional (1-D) heat conduction model (Cuffey and Paterson, 2010) was used to infer the geothermal heat flux required to satisfy $\mathrm{BH} 1$ ice temperature observations with known ice geometry and surface mass balance. The 1-D heat conduction model suggests a geothermal heat flux of $\sim 18.5 \mathrm{~mW} \mathrm{~m}^{-2}$. This geothermal heat flux was applied to the entire ERG model domain.
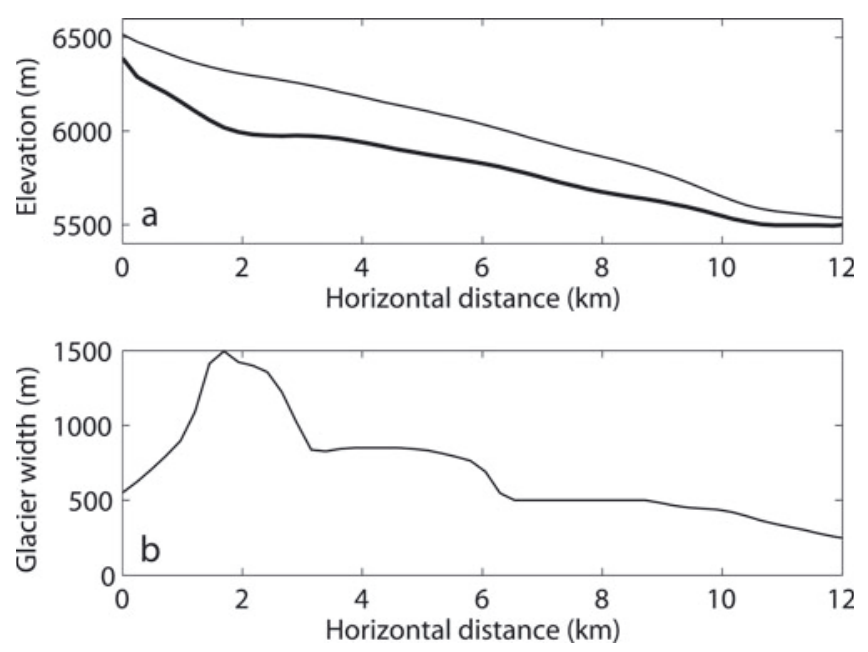

Fig. 4. (a) The glacier geometry along the MFL of ERG. The thin and thick lines denote glacier surface and base, respectively. (b) The glacier width along the MFL of ERG. 


\section{MODEL DESCRIPTION}

\subsection{Ice flow model}

Here we briefly describe the 2-D higher-order flowband model that we use in this study. A complete model description can be found in Pimentel and others (2010) and Flowers and others (2011). In a Cartesian coordinate system (where $x$ is the horizontal axis oriented down-glacier and $z$ is the vertical axis oriented upward), the 2-D force balance equations are

$$
\begin{gathered}
\frac{\partial \sigma_{x x}}{\partial x}+\frac{\partial \sigma_{x z}}{\partial z}+F=0, \\
\frac{\partial \sigma_{z x}}{\partial x}+\frac{\partial \sigma_{z z}}{\partial z}=\rho g,
\end{gathered}
$$

where $\sigma_{i j}$ (for $i, j=x, z$ ) are the components of the stress tensor, $\rho$ is ice density, $g$ is gravitational acceleration and $F$ is the lateral shear stress gradient that is missing in the standard 2-D (plane-strain) force balance equations. Constants used in the numerical model are listed in Table 1. Based on the hydrostatic approximation and a stress-free condition at the glacier surface (Blatter, 1995), we express the force balance equation as

$$
\frac{\partial}{\partial x}\left(2 \sigma_{x x}^{\prime}+\sigma_{y y}^{\prime}\right)+\frac{\partial \sigma_{x z}}{\partial z}+F=\rho g \frac{\partial s}{\partial x},
$$

where $\sigma_{i j}^{\prime}$ (for $i, j=x, z$ ) denotes the components of the deviatoric stress tensor and $s$ is the ice surface elevation. Following Flowers and others (2011), we assume no lateral slip or slide along valley walls, and parameterize $F$ as

$$
F \simeq-\frac{\eta u}{W^{2}}
$$

where $\eta$ is temperature and strain-rate-dependent effective viscosity of ice, $u$ is the horizontal velocity along the $x$ direction and $W(x, z)$ is the flowband half-width. We take the $y$-axis orthogonal to the MFL with $y=0$ at the MFL. The effective viscosity of ice is given by

$$
\eta=\frac{1}{2} A^{-\frac{1}{n}}\left(\dot{\epsilon}_{\mathrm{e}}^{2}+\dot{\epsilon}_{0}^{2}\right)^{\frac{1-n}{2 n}},
$$

where $\dot{\epsilon}_{\mathrm{e}}$ is effective strain rate, $\dot{\epsilon}_{0}$ is a small value used to avoid numerical singularity, $n$ is the flow law exponent, and $A$ is a temperature-dependent flow law parameter, described by the Arrhenius-type relation

$$
A=A_{0} \exp \left(-\frac{Q}{R T}\right),
$$

with $A_{0}$ a reference flow law parameter, $Q$ the creep activation energy of ice, $R$ the universal gas constant and $T$ the ice temperature $(K)$. The effective strain rate can be calculated as (Greve and Blatter, 2009)

$$
\dot{\epsilon}_{\mathrm{e}}^{2} \simeq\left(\frac{\partial u}{\partial x}\right)^{2}+\left(\frac{\partial v}{\partial y}\right)^{2}+\frac{\partial u}{\partial x} \frac{\partial v}{\partial y}+\frac{1}{4}\left(\frac{\partial u}{\partial y}\right)^{2}+\frac{1}{4}\left(\frac{\partial u}{\partial z}\right)^{2},
$$

where $v$ is the horizontal velocity along the $y$ direction.

\begin{tabular}{|c|c|c|c|}
\hline Symbol & Constant & Value & Unit \\
\hline$\beta$ & Clausius-Clapeyron constant & $8.7 \times 10^{-4}$ & $\mathrm{Km}^{-1}$ \\
\hline$\rho$ & Ice density & 917 & $\mathrm{~kg} \mathrm{~m}^{-3}$ \\
\hline$\rho_{\mathrm{w}}$ & Water density & 1000 & $\mathrm{~kg} \mathrm{~m}^{-3}$ \\
\hline$g$ & Gravitational acceleration & 9.8 & $\mathrm{~ms}^{-2}$ \\
\hline$n$ & Flow law exponent & 3 & \\
\hline \multirow[t]{2}{*}{$A_{0}$} & Flow law parameter & & \\
\hline & $\begin{array}{l}\text { when } T \leq 263.15 \mathrm{~K} \\
\text { when } T>263.15 \mathrm{~K}\end{array}$ & $\begin{array}{c}3.985 \times 10^{-13} \\
1.916 \times 10^{3}\end{array}$ & $\mathrm{~s}^{-1} \mathrm{~Pa}^{-3}$ \\
\hline C & Heat capacity of ice & 2009 & $\mathrm{Jg}^{-1} \mathrm{~K}^{-1}$ \\
\hline \multirow[t]{3}{*}{$Q$} & Creep activation energy & & \\
\hline & when $T \leq 263.15 \mathrm{~K}$ & 60 & $\mathrm{~kJ} \mathrm{~mol}-1$ \\
\hline & when $T>263.15 \mathrm{~K}$ & 139 & $\mathrm{KJ \textrm {mol }}$ \\
\hline K & Thermal conductivity of ice & 2.1 & $W m^{-1} K^{-1}$ \\
\hline$L$ & Latent heat of fusion of ice & $3.35 \times 10^{5}$ & $\mathrm{Jkg}^{-1}$ \\
\hline$R$ & Universal gas constant & 8.31 & $\mathrm{~J} \mathrm{~mol}^{-1} \mathrm{~K}^{-1}$ \\
\hline$T_{0}$ & Triple point of water & 273.15 & K \\
\hline
\end{tabular}
Taking $\partial v / \partial y=u / W \cdot \partial W / \partial x$ (Nye, 1959; Flowers and others, 2011), we rewrite Eqn (3) as follows:

$$
\begin{aligned}
& \frac{u}{W}\left\{2 \frac{\partial \eta}{\partial x} \frac{\partial W}{\partial x}+2 \eta\left[\frac{\partial^{2} W}{\partial x^{2}}-\frac{1}{W}\left(\frac{\partial W}{\partial x}\right)^{2}\right]-\frac{\eta}{W}\right\} \\
& +\frac{\partial u}{\partial x}\left(4 \frac{\partial \eta}{\partial x}+\frac{2 \eta}{W} \frac{\partial W}{\partial x}\right)+\frac{\partial u}{\partial z} \frac{\partial \eta}{\partial z}+4 \eta \frac{\partial^{2} u}{\partial x^{2}}+\eta \frac{\partial^{2} u}{\partial z^{2}}=\rho g \frac{\partial s}{\partial x}
\end{aligned}
$$

Table 1. List of parameters and values prescribed for the experiments, and some other symbols

where the effective viscosity of ice can be expressed as

$$
\begin{aligned}
\eta=\frac{1}{2} A^{-\frac{1}{n}} & {\left[\left(\frac{\partial u}{\partial x}\right)^{2}+\left(\frac{u}{W} \frac{\partial W}{\partial x}\right)^{2}+\frac{u}{W} \frac{\partial u}{\partial x} \frac{\partial W}{\partial x}\right.} \\
& \left.+\frac{1}{4}\left(\frac{\partial u}{\partial z}\right)^{2}+\frac{1}{4}\left(\frac{u}{W}\right)^{2}+\dot{\epsilon}_{0}^{2}\right]^{\frac{1-n}{2 n}} .
\end{aligned}
$$

\subsection{Ice temperature model}

In order to assess the present-day ice temperature distribution along the MFL of ERG, we assume a thermal steadystate condition, whereby the 2-D energy-balance equation including the horizontal diffusion becomes (Pattyn, 2002)

$$
u \frac{\partial T}{\partial x}+w \frac{\partial T}{\partial z}-\frac{K}{\rho c}\left(\frac{\partial^{2} T}{\partial x^{2}}+\frac{1}{W} \frac{\partial W}{\partial x} \frac{\partial T}{\partial x}+\frac{\partial^{2} T}{\partial z^{2}}\right)-\frac{E}{\rho c}=0,
$$

where $K$ is the conductivity of ice, $C$ is the heat capacity of ice and $E$ is the strain heat produced by internal deformation (Greve and Blatter, 2009)

$$
E=4 \eta \dot{\epsilon}_{\mathrm{e}}^{2} .
$$

The vertical ice velocity, $w$, is solved directly from the incompressibility condition (e.g. Pattyn, 2002)

$$
w(z)=w(b)-\int_{b}^{z}\left(\frac{\partial u}{\partial x}+\frac{u}{W} \frac{\partial W}{\partial x}\right) d z,
$$

where $b$ is the elevation of the glacier bed.

The pressure-melting-point of glacier ice, $T_{\mathrm{pmp}}$, is described by the Clausius-Clapeyron relation

$$
T_{\mathrm{pmp}}(z)=T_{0}-\beta(s-z),
$$

where $T_{0}$ is the triple point of water and $\beta$ is the ClausiusClapeyron constant. A CTS is located at the depth where ice colder than $T_{\text {pmp }}$ is in contact with temperate ice at $T_{\text {pmp }}$. The ice flowing across the CTS can be assumed to have a negligible water content where cold ice flows into the temperate ice zone (TIZ) (Blatter and Hutter, 1991; Greve and Blatter, 2009). Thus, in this case, the ice temperature gradient at the CTS is equal to the Clausius-Clapeyron gradient (Funk and others, 1994). The temperate ice flowing across the CTS from the TIZ into cold ice, however, cannot 
be assumed to have a negligible water content. The trace water contained in the temperate ice will refreeze and release latent heat $Q_{\mathrm{r}}$ as it crosses the CTS:

$$
Q_{\mathrm{r}}=w \theta \rho_{\mathrm{w}} L,
$$

where $\theta$ is the fractional water content of the temperate ice, $\rho_{\mathrm{w}}$ is the density of water and $L$ is the latent heat of freezing of water (Greve and Blatter, 2009). Thus, in this case, the ice temperature gradient at the CTS may be described by (Funk and others, 1994)

$$
\frac{\partial T}{\partial z}=-\frac{Q_{r}}{K}+\beta
$$

Due to the presence of $Q_{r}$, the vertical location of the CTS must be determined by numerical iteration (Funk and others, 1994; see Section 3.4 below).

\subsection{Boundary conditions}

In the ice flow model, the upstream and downstream boundary conditions are both zero ice velocities. The upper boundary condition is a stress-free surface (Blatter, 1995; Flowers and others, 2011) while the lower boundary condition is a phenomenological friction law (Gagliardini and others, 2007; Flowers and others, 2011)

$$
\tau_{\mathrm{b}}=\Gamma\left(\frac{u_{\mathrm{b}}}{u_{\mathrm{b}}+\Gamma^{n} N^{n} \Lambda}\right)^{\frac{1}{n}} N, \quad \Lambda=\frac{\lambda_{\max } A}{m_{\max }},
$$

where $\tau_{\mathrm{b}}$ is the basal drag, $\Gamma$ is a constant, $u_{\mathrm{b}}$ is the sliding velocity, $N$ is the basal effective pressure, $\lambda_{\max }$ is the dominant wavelength of bed bumps and $m_{\max }$ is their maximum slope. We take $\Gamma=0.84 m_{\max }$, assuming a sinusoidal bedrock geometry (e.g. Gagliardini and others, 2007). The basal effective pressure $N$ is defined as

$$
N=\rho g H-P_{\mathrm{w}}=\phi \rho g H,
$$

where $H$ is ice thickness and $P_{\mathrm{w}}$ is the basal water pressure. We use a factor $\phi$ to represent the effective basal pressure as a fraction of total ice overburden pressure. The basal drag is defined as the sum of all resistance stress at the glacier bed (Van der Veen and Whillans, 1989; Pattyn, 2002). Neglecting the basal melt rate, the vertical velocity at the glacier bed can be calculated according to the basal kinematic boundary condition (Greve and Blatter, 2009)

$$
w(b)=u_{\mathrm{b}} \frac{\partial b}{\partial x} \text {. }
$$

The upper boundary condition of the ice temperature model is mean annual air temperature, while the lower boundary condition is a prescribed geothermal heat flux, $G$ :

$$
\frac{\partial T}{\partial z}=-\frac{G}{K} \quad \text { at } \quad z=b .
$$

At the glacier head $(\mathrm{km0})$, the vertical ice temperature profile is derived from a 1-D solution of the energy-balance equation assuming negligible horizontal advection.

\subsection{Numerical method}

The numerical calculation of $u$ may produce a singularity at the glacier bed (Eqn (8)), where $W=0$, if we parameterize the shape of a glacier valley using a power law function, $z(y)=p y^{q}$. To avoid a numerical singularity, we prescribe $W$ at the glacier bed, $W(x, b)$, as a small fraction, $\chi$, of the nonzero $W$ of the gridpoint above, $W(x, b+\Delta z)$ :

$$
W(x, b)=\chi W(x, b+\Delta z) .
$$

Neglecting the contribution of $\sigma_{x x}^{\prime}$ and $\sigma_{y y}^{\prime}$ to the basal drag
(Adhikari and Marshall, 2011), we can express the basal sliding boundary condition as follows (Pimentel and others, 2010):

$$
\frac{1}{2 A}\left[\frac{\partial u}{\partial z}(b)\right]^{l+1}-\frac{\Gamma^{n} N^{n} m_{\max }}{u_{\mathrm{b}}^{l} m_{\max }+N^{n} \lambda_{\max } A} u_{\mathrm{b}}^{l+1}=0,
$$

where $/$ is the iteration number.

For the temperature model, the CTS depth is determined differently where vertical ice velocities at the CTS are downward and upward. Under the condition in which cold ice flows downwards across the CTS into the TIZ, if the calculated ice temperature exceeds the pressure-melting point (i.e. $T>T_{\mathrm{pmp}}$ ), the ice temperature is set to the pressure-melting point. This assumes that any excess heat is absorbed by the latent heat associated with melting. Under the condition in which temperate ice flows upwards across the CTS into the cold ice zone, however, the latent heat released by refreezing, $Q_{r}$, at the CTS must be taken into consideration. If $Q_{r}$ is sufficient to raise the ice temperature of the gridpoint above the CTS to the pressure-melting point,

$$
\frac{\partial T}{\partial z} \geq-\frac{Q_{r}}{K}+\beta \quad \text { at the CTS, }
$$

the CTS is raised by one gridpoint. The vertical ice temperature profile is iteratively recalculated with the modified CTS grid position until the CTS node position no longer changes between iterations (Funk and others, 1994).

For numerical convenience, we adopt a terrain-following coordinate system (e.g. Pattyn, 2003)

$$
\zeta=\frac{z-b}{H},
$$

with $\zeta=0$ at the glacier bed and $\zeta=1$ at the glacier surface. We apply a 51 (horizontal) $\times 21$ (vertical) grid to the longitudinal cross-section profile of ERG. A second-order, gridpoint-centred, finite-difference scheme is applied to discretize Eqn (8). The energy-balance equation (Eqn (10)) is discretized using first-order upstream differences in the horizontal, and node-centred differences in the vertical. The ice temperature field is sequentially solved, in column-bycolumn fashion, from the glacier head to the terminus. Ice viscosity and temperature are initialized as $\eta=10^{13}$ Pas (Zwinger and Moore, 2009) and $-5^{\circ} \mathrm{C}$ (based on in situ ice temperatures at boreholes $\mathrm{BH} 1, \mathrm{BH} 2$ and $\mathrm{BH} 3)$, respectively. Both the ice temperature and velocity fields of the entire longitudinal cross-section profile are then determined by a relaxed Picard subspace iteration scheme following De Smedt and others (2010). Denoting $\mathbf{u}_{*}^{l}$ and $\mathbf{u}^{\prime}$ as the $/$ th velocity field from true Picard iteration and the relaxed Picard subspace iteration, respectively, we have good numerical convergence when the velocity field satisfies the condition (De Smedt and others, 2010)

$$
\frac{\left\|\mathbf{u}_{*}^{l}-\mathbf{u}^{l-1}\right\|}{\left\|\mathbf{u}_{*}^{l}\right\|}<10^{-4} \text {. }
$$

\section{RESULTS AND DISCUSSION}

\subsection{Model sensitivity}

We perform diagnostic modelling experiments to simulate the present-day ice velocity and temperature distribution along the MFL of ERG. Our model has six free parameters: (1) friction law parameter $m_{\max }$ (2) friction law parameter $\lambda_{\text {max }}$ (3) effective basal pressure fraction $\phi$, (4) basal width 

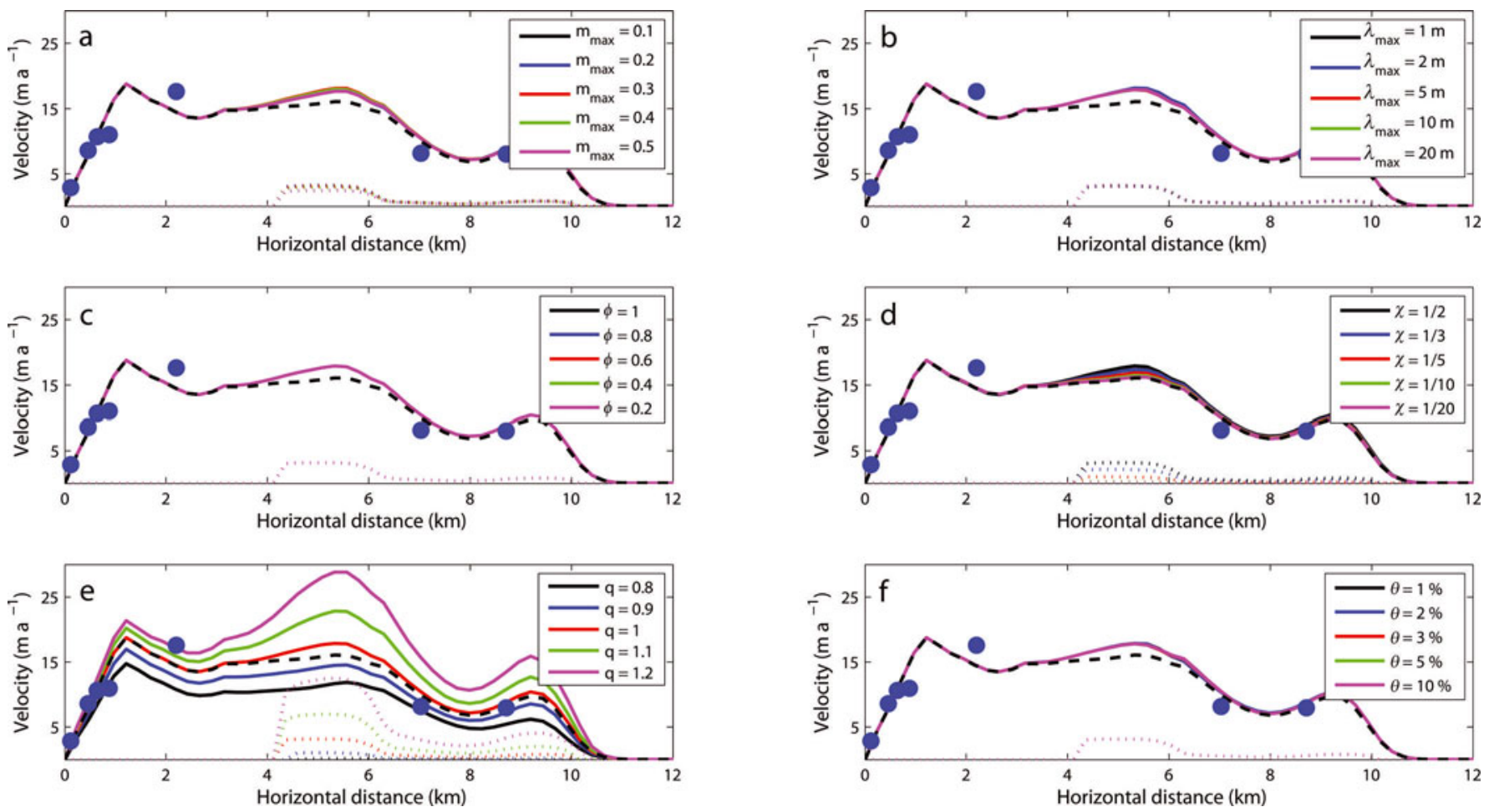

Fig. 5. Sensitivity experiments of ice velocity along the MFL. We vary only one parameter at a time, while holding the other five fixed at the values we use in our model $\left(m_{\max }=0.2, \lambda_{\max }=5 \mathrm{~m}, \phi=1, \chi=1 / 2, q=1\right.$ and $\theta=1 \%$ ). The solid, dotted and black dashed lines denote surface velocity, basal sliding velocity and surface velocity under a no-slip scenario with $q=1$ (V-shaped glacial valley), respectively. The solid circles denote in situ measurements of mean annual surface ice velocity obtained from the stakes located on or near the MFL (see Fig. 2).

fraction $\chi,(5)$ glacial valley shape index $q$ and (6) fractional water content in temperate ice $\theta$. In a series of numerical experiments (Figs 5 and 6), we explore the independent impact of each of these parameters on the model sensitivity by varying only one at a time while holding the other five fixed at the values we use in our model $\left(m_{\max }=0.2\right.$, $\lambda_{\max }=5 \mathrm{~m}, \phi=1, \chi=1 / 2, q=1$, and $\theta=1 \%$ ).

The friction law parameters, $m_{\max }$ and $\lambda_{\max }$, represent the maximum slope and wavelength of basal roughness, respectively. Basal sliding velocity, $u_{\mathrm{b}}$, is expected to increase as $m_{\max }$ decreases (Fig. 5a) and $\lambda_{\max }$ increases (Fig. 5b) (Flowers and others, 2011). For a sinusoidal glacier bed with cavities, we may find that $m_{\max }$ is raised to a greater power $\left(n+1, \Gamma^{n} m_{\max }\right)$ than $\lambda_{\max }(1)$ in the friction law (Schoof, 2005; Flowers and others, 2007; Gagliardini and others, 2007; Eqn (21)). As a result, $u_{\mathrm{b}}$ is more sensitive to $m_{\max }$ than $\lambda_{\max }$ (Fig. 5a and b).

The effective pressure, $N$, determined as the ratio between ice and water pressures, appears to have little influence on basal sliding for such a narrow glacial valley (Fig. 5c). From Eqn (21) we know that the value of $\partial u / \partial z(b)$, which is coupled to the momentum balance equation (Eqn (8)), depends on the relative magnitudes of $u_{\mathrm{b}} / N^{n}$ and $\lambda_{\max } A / m_{\max }$. Thus, a relatively narrow glacial valley (small $u_{\mathrm{b}}$ ), a relatively large ice thickness (large $N$ ) and flow law parameter may produce a $u_{\mathrm{b}} / N^{n}$ term that is negligible in comparison to the magnitude of the $\lambda_{\max } A / m_{\max }$ term. This would render the influence of the effective basal pressure factor, $\phi$, less important. This is possibly the reason why Flowers and others (2011) found that values of $m_{\max }$ and $\lambda_{\max }$ strongly affected their selection of the best value of $N$ for a good simulation of ice velocities.
We further see the critical role that glacial valley plays in modulating basal sliding in Figure $5 \mathrm{~d}$ and e. As the glacier bed becomes flatter, which is parameterized by increasing the $\chi$ parameter, basal sliding velocity increases. Modelled ice surface velocity appears to be most sensitive to varying the cross-sectional valley profile via $q$. Varying $q$ between 0.8 and 1.2 produces the widest velocity sensitivity range of the six parameters examined. Modelled ice temperature, which is coupled to modelled ice velocity, is also more sensitive to the prescribed cross-sectional valley profile (Fig. 6e) than $m_{\max }, \lambda_{\max }$ and $N$ (Fig. 6a-d). Figure 7 provides a comparison between modelled and observed ice temperatures in shallow boreholes, BH2 $(17.5 \mathrm{~m}$ deep at $6350 \mathrm{~m}$ a.s.I., $\mathrm{km} \mathrm{1.7)} \mathrm{and} \mathrm{BH3} \mathrm{(18} \mathrm{m}$ deep at $5710 \mathrm{~m}$ a.s.I., km 9.8), over a range of chosen values of $q$.

We assume that the rate factor $A$ is independent of water content $\theta$ (Eqn (6)), so the sensitivity of $u_{\mathrm{b}}$ to water content, $\theta$, is small (Fig. 5f). A significant increase in water content only slightly increases the length of the TIZ (Fig. 6f). We attribute this insensitivity to relatively small vertical ice velocities $\left(<0.1 \mathrm{~m} \mathrm{a}^{-1}\right.$ in the $\left.\mathrm{TIZ}\right)$, which render the latent heat term of the heat equation insensitive to most parameters, including water content (Eqn (14)).

Based on the sensitivity experiments described above, we adopt $m_{\max }=0.2, \quad \lambda_{\max }=5 \mathrm{~m}, \phi=1 \quad$ (no basal water pressure), $\chi=1 / 2, q=1$ (a V-shaped glacial valley) and $\theta=1 \%$ (typical of temperate ice; Cuffey and Paterson, 2010) as the parameter suite that best simulates the present-day ice velocity and temperature distributions of ERG.

\subsection{Model results}

Using the numerical model and parameter suite described above, we simulate the present-day ice velocity and 

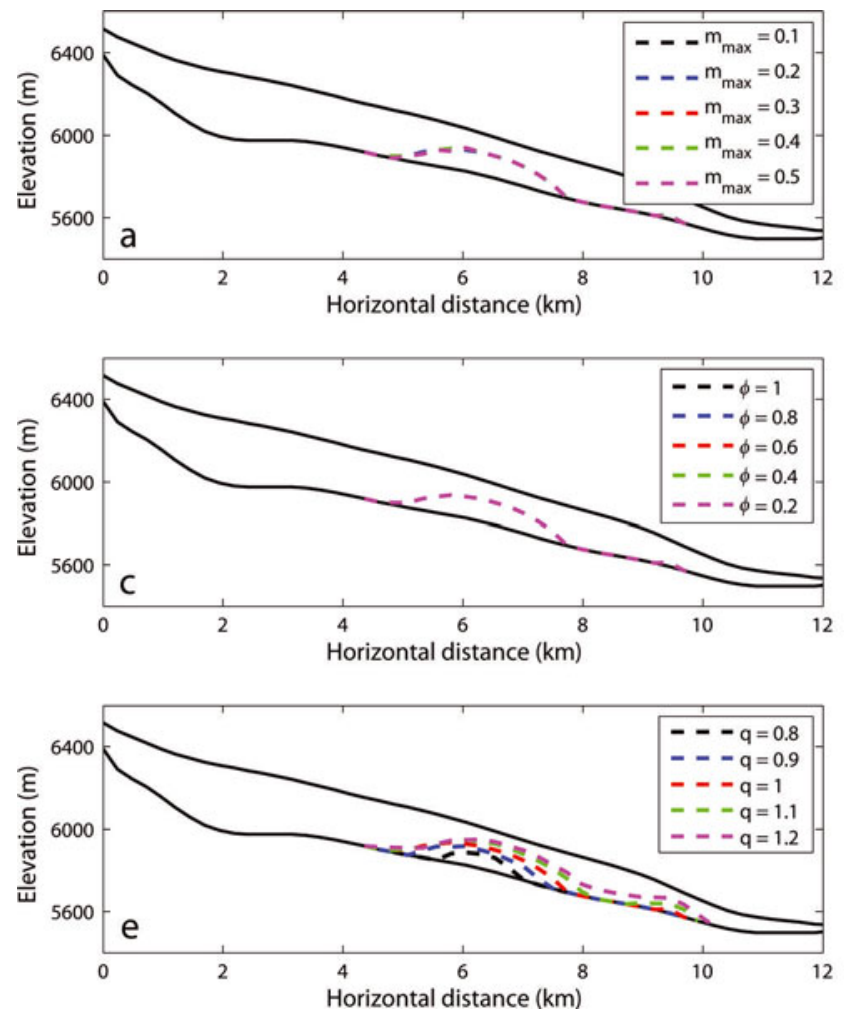
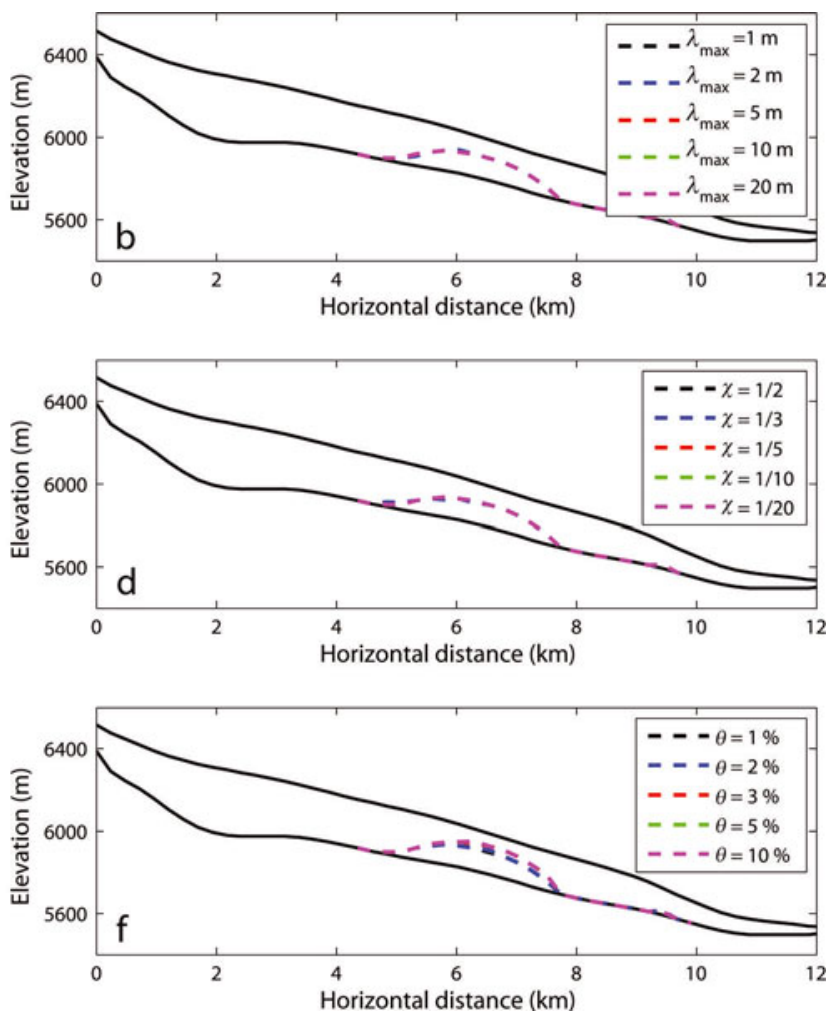

Fig. 6. Sensitivity experiments of the size of TIZ (dashed lines). The parameter setting is the same as in Figure 5.

temperature distributions in the longitudinal cross-sectional profile along the MFL of ERG (Fig. 8).

The modelled ice surface velocities generally agree well with the observed mean annual velocities under the parameter suite we adopt (Fig. 5). However, since the numerical simulations ignore the influxes stemming from ERG tributaries, the modelled ice surface velocities do underestimate observed ice surface velocities at $\mathrm{km} 2$, where the largest tributary converges with the MFL (Fig. 2). Figure 5 suggests that basal sliding may influence ice flow over a more extensive region than the $\mathrm{TIZ}$, which was also

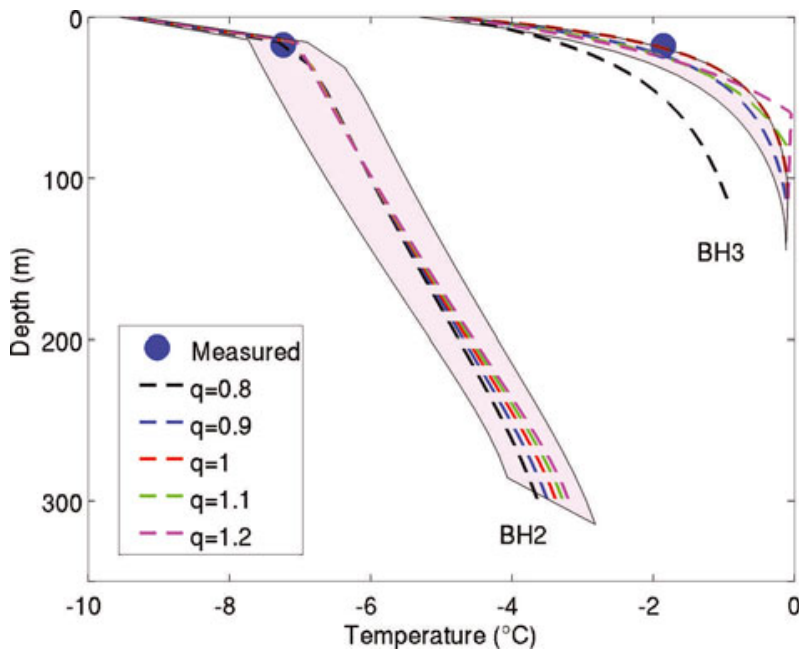

Fig. 7. Comparison of measured and modelled ice temperature at $\mathrm{BH} 2$ and $\mathrm{BH}$. The shaded areas denote ice temperature ranges for \pm 1 gridpoints upstream and downstream of $\mathrm{BH} 2$ and $\mathrm{BH} 3$ with $q=1$. suggested by Pimentel and others (2010). The observation of seasonal velocity variations at $5775 \mathrm{~m}$ a.s.l. ( $\mathrm{km} \mathrm{9.1;} \mathrm{see}$ Section 2.1) provides independent support for the notion of a basal TIZ (Colgan and others, 2012). Overall, however, basal sliding likely contributes a minor portion $(<20 \%)$ of mean annual ice velocity at ERG. The flow of ERG is dominated by slow internal deformation. The internal deformation rate is slow mainly due to the relatively small ice thickness $(<320 \mathrm{~m})$, the relatively narrow glacier valley (large lateral drag) and high-elevation (cold atmosphere) setting of ERG. The narrow glacial valley cross section of ERG is itself
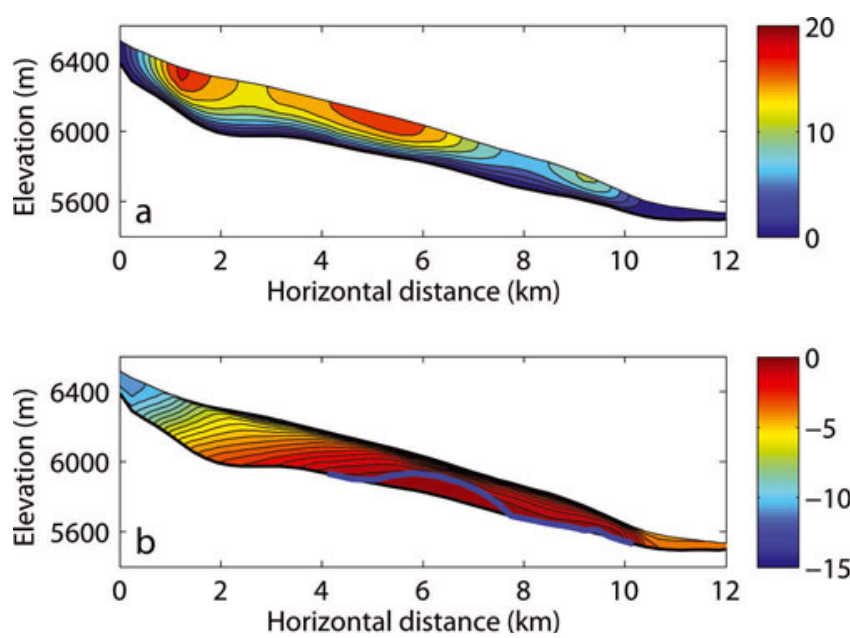

Fig. 8. Modelled distribution of (a) horizontal ice velocity $\left(\mathrm{m} \mathrm{a}^{-1}\right)$ and (b) temperature $\left({ }^{\circ} \mathrm{C}\right.$ ) along the MFL of ERG. The thick blue line denotes the CTS. 

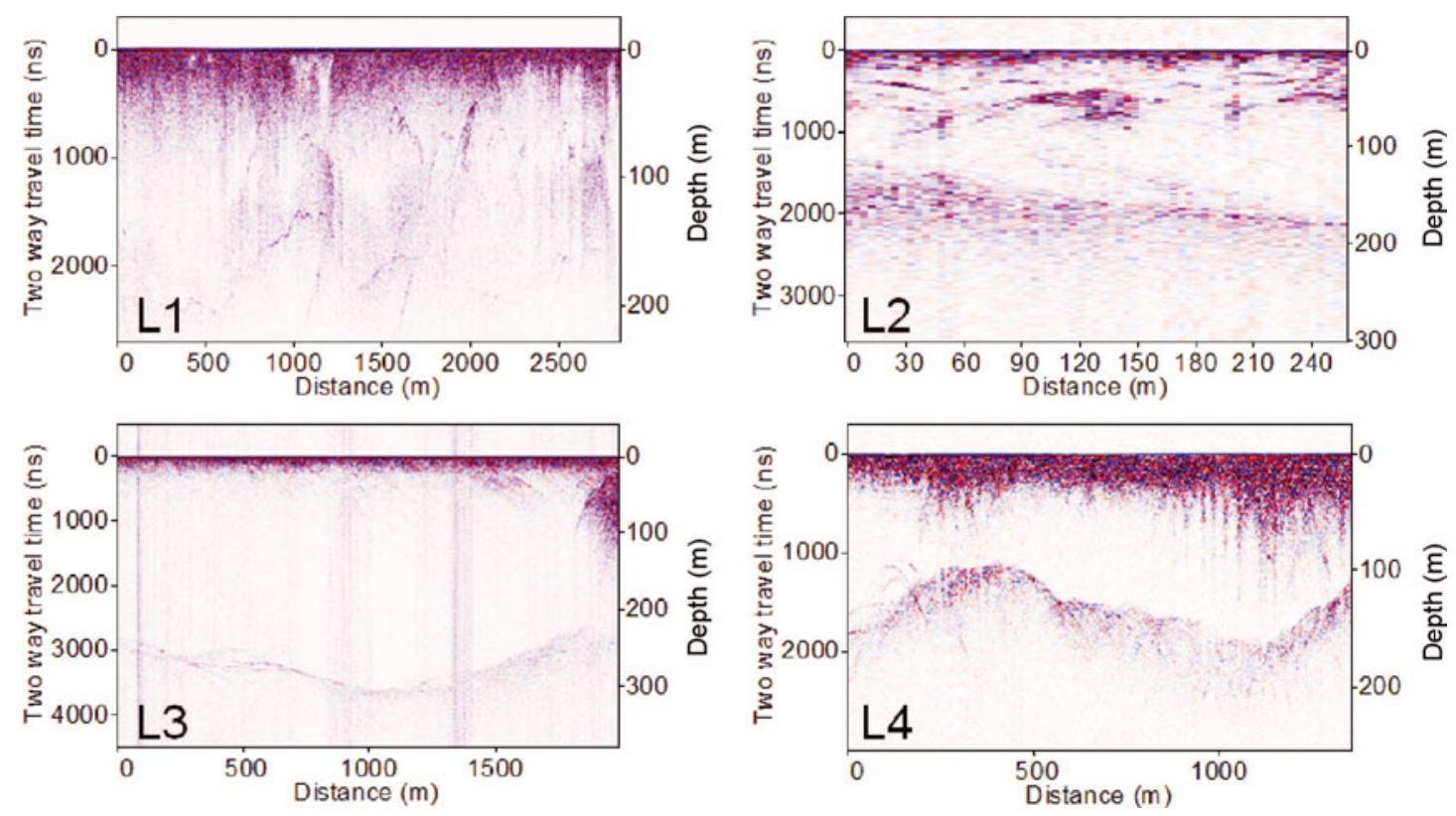

Fig. 9. GPR energy is scattered near the glacier bed in the downstream ablation zone (L1 and L2), which we interpret as indicating the presence of temperate basal ice. In the upstream portion of ERG (L3 and L4), a clean glacier bed can be identified, suggesting the presence of cold basal ice. The locations of L1-L4 are shown in Figure 2.

independent support for relatively little basal sliding. Significant basal sliding would be expected to enhance basal erosion (Harbor, 1992, 1995), which would have allowed ERG to have evolved to the broad U-shaped valley cross section characteristic of alpine glaciers.

The model suggests the existence of an extensive TIZ, $\sim 6 \mathrm{~km}$ in length from around 5700 to $6200 \mathrm{~m}$ a.s.l. $(\mathrm{km} 4-$ $10)$, in the basal ice of the ERG upper ablation zone. The accumulation zone and the terminus of ERG, however, are still underlain by cold ice. Thus, we suggest ERG is a polythermal glacier. Modelled ice temperature agrees well with the deepest available ice temperature measurements in two shallow ice boreholes ( $\mathrm{BH} 2$ at $17.5 \mathrm{~m}$ and $\mathrm{BH} 3$ at $18 \mathrm{~m}$ ) at 6350 ( $\mathrm{km} \mathrm{1.7)} \mathrm{and} 5710 \mathrm{~m}$ a.s.l. (km 9.8) (Fig. 7). No deep, near-bedrock, ice temperature measurements are presently available for comparison with modelled ice temperature. The GPR data obtained in May 2009, however, exhibit reflectance variations that we interpret as resulting from differences in the thermal character of cold up-glacier and warm down-glacier regions (Figs 2 and 9). In the up-glacier region, a continuous glacier bed is clearly visible in 'clean'

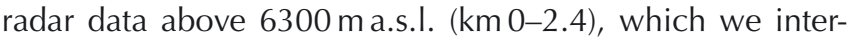
pret as evidence of cold basal ice (e.g. Irvine-Fynn and others, 2006). In the down-glacier region, radar energy is scattered. The radargram near the glacier bed appears noisy near the terminus, in the 5760-6020 m a.s.l. elevation band $(\mathrm{km}$ 5.3-9.2). We interpret this region of scattered radar energy as independent support of a substantial basal TIZ (e.g. Irvine-Fynn and others, 2006).

For ERG, the existence of a relatively large warm base is partly due to its small accumulation basin. From the in situ observations during 2009-11, the present-day surface massbalance equilibrium-line altitude of ERG is $\sim 6400 \mathrm{~m}$ a.s.I. $(\mathrm{km} \mathrm{1})$, and the accumulation zone presently comprises only $8 \%$ of the total glacier length. As a result, the advection of cold ice from the accumulation zone only influences (i.e. 'cools down') the ice temperature of a very small portion of the ablation region.
As a sensitivity test to examine the permanence of the $\mathrm{TIZ}$, we decreased geothermal heat flux and mean annual air temperature to simulate a much colder environmental setting. This test demonstrated that a small TIZ (thinner than the thickness of one grid layer) exists in the downstream ablation zone ( $\mathrm{km} \mathrm{7-10),} \mathrm{even} \mathrm{under} \mathrm{a} \mathrm{prescribed} \mathrm{mean}$ annual air temperature at $5708 \mathrm{~m}$ a.s.l. $\left(\mathrm{km} \mathrm{9.8)} \mathrm{of}-7^{\circ} \mathrm{C}\left(2^{\circ} \mathrm{C}\right.\right.$ lower than the present surface air temperature; Fig. 10a) or a prescribed geothermal heat flux of only $9 \mathrm{~mW} \mathrm{~m}^{-2}$ (around half of the present geothermal heat flux; Fig. 10c). Accordingly, the TIZ grows larger when we prescribe larger geothermal heat fluxes and surface air temperatures (Fig. $10 \mathrm{~b}$ and d). On ERG, the size of the TIZ appears to be more sensitive to surface air temperature than to geothermal heat flux (Fig. 10). Thus, we speculate that basal temperate ice zones are likely a common feature of large valley glaciers like the ERG in the Qomolangma region.

\subsection{Model limitations}

Although the true cross-sectional valley shape of ERG is believed to approximate a V-shape (Zhang and others, 2012), imposing an idealized V-shaped cross section in our model is an assumption that is only supported by inferences, not actual observations. Since basal water pressure and the true bed geometry are not known, $\phi, \chi$ and the bed roughness parameters in the friction law, i.e. $m_{\max }, \lambda_{\max }$ and $\Gamma$, cannot be constrained based on the observations. To address this limitation, we have examined a wide range of values for these parameters in our sensitivity experiments. Additionally, as our model ignores all tributaries, we cannot assess the lateral flow effects stemming from tributary convergence. Furthermore, because of the lack of 3-D glacier geometry information, we use a 2-D ice flow model. As a compromise, we parameterize lateral drag with the glacier width variations. Finally, the ice temperature model is 2-D, and thus neglects horizontal advection in the $y$ direction. In our 2-D model, it is difficult to simulate the lateral sliding since we lack any knowledge of the 

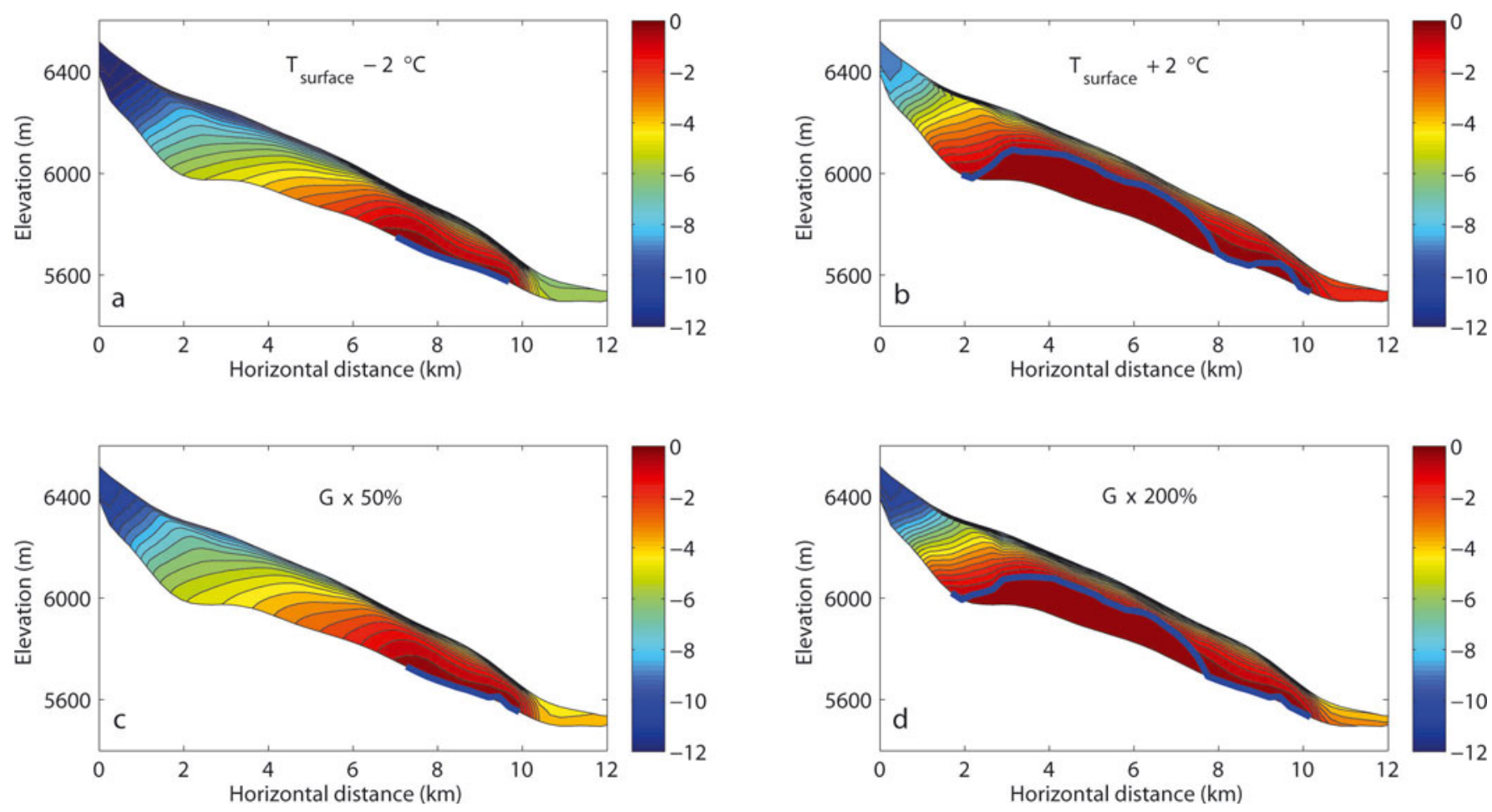

Fig. 10. Sensitivity studies of the ERG TIZ size under scenarios of (a) $G=18.5 \mathrm{~mW} \mathrm{~m}^{-2}, T_{5708}=-7^{\circ} \mathrm{C}$; (b) $G=18.5 \mathrm{~mW} \mathrm{~m}^{-2}, T_{5708}=-3^{\circ} \mathrm{C}$; (c) $G=9 \mathrm{~mW} \mathrm{~m}^{-2}, T_{5708}=-5^{\circ} \mathrm{C}$; and (d) $G=37 \mathrm{~mW} \mathrm{~m}^{-2}, T_{5708}=-5^{\circ} \mathrm{C}$. The temperature values are in Celsius. The thick blue lines denote the CTS.

distribution of CTS along the glacial valley walls. However, this may not introduce much error because (1) lateral sliding is an unimportant factor influencing ice flow compared to glacier width (Pimentel and others, 2010) (except for the cases of glaciers with detached side walls; Adhikari and Marshall, 2012) and (2) ERG is a relatively cold glacier with narrow cross-sectional valleys and thus small sliding velocities.

\section{CONCLUSIONS}

For large alpine valley glaciers with few in situ observations available, it is difficult to construct a suitable glacier model with both reliability and simplicity. The 2-D higher-order thermomechanical flowband model presented here requires much fewer input data than a 3-D high-order or full-Stokes model. Nevertheless, it can simulate most glacier dynamic features (e.g. the longitudinal stress gradient coupling, lateral drag, basal sliding velocity and CTS), and thus is a good option for large glacier modelling.

The strong ablation, due to large solar radiation and a warming climate (TSECAS, 1975; Hock, 2003; Pellicciotti and others, 2005; Huss and others, 2009), leads to a small accumulation zone on ERG. As a result, the vertical velocity is presently upwards throughout most of the glacier, facilitating the upward advection of warm basal ice throughout the oversized ablation zone. There are at least two important implications of a basal TIZ. Firstly, temperate ice allows an active englacial hydrology system to exist (Fountain and Walder, 1998). An active englacial hydrology system allows surface ablation to route through a glacier without being retained by refreezing. This has implications for land-terminating Himalayan glaciers whose mass loss occurs only by surface ablation and runoff. Secondly, temperate ice and meltwater facilitate basal sliding (Bartholomaus and others, 2008). A potential enhancement of basal sliding with warming climate is expected to transport more ice to lower-elevation areas where higher surface ablation occurs.

While it has been speculated that the ablation zones of large continental valley glaciers in the Qomolangma region contain basal ice at the pressure-melting-point (TSECAS, 1975; Huang, 1999), our study is the first modelling support for this hypothesis. In addition, this study is also the first to model a large valley glacier located on the northern slope of the Himalayan range. Work is currently underway to develop a fully transient prognostic version of the model, in order to predict the ice geometry, velocity and temperature of ERG under future climate scenarios.

\section{ACKNOWLEDGEMENTS}

This study is funded by National Fundamental Research Project (973) of China (2007CB411503) and National Science Foundation of China (NSFC). We are grateful to all members of the scientific expedition to Qomolangma for their dedication to the extraordinarily hard fieldwork. We also thank Konrad Steffen for supporting T.Z.'s visit to CIRES to learn glacier modelling. We thank Heinz Blatter, Mathieu Morlighem, Arne Keller, Surendra Adhikari, Ian Allison and an anonymous reviewer for their reviews of an earlier version of this paper. Weili Wang was our scientific editor.

\section{REFERENCES}

Adhikari S and Huybrechts P (2009) Numerical modelling of historical front variations and the 21st-century evolution of 
glacier AX010, Nepal Himalaya. Ann. Glaciol., 50(52), 27-40 (doi: 10.3189/172756409789624346)

Adhikari S and Marshall SJ (2011) Improvements to sheardeformational models of glacier dynamics through a longitudinal stress factor. J. Glaciol., 57(206), 1003-1016 (doi: 10.3189/002214311798843449)

Adhikari S and Marshall SJ (2012) Parameterization of lateral drag in flowline models of glacier dynamics. J. Glaciol., 58(212), 1119-1132 (doi: 10.3189/2012JoG12J018)

Barnett TP, Adam JC and Lettenmaier DP (2005) Potential impacts of a warming climate on water availability in snow-dominated regions. Nature, 438(7066), 303-309 (doi: 10.1038/ nature04141)

Bartholomaus TC, Anderson RS and Anderson SP (2008) Response of glacier basal motion to transient water storage. Nature Geosci., 1(1), 33-37 (doi: 10.1038/ngeo.2007.52)

Blatter H (1995) Velocity and stress fields in grounded glaciers: a simple algorithm for including deviatoric stress gradients. J. Glaciol., 41(138), 333-344

Blatter H and Hutter K (1991) Polythermal conditions in Arctic glaciers. J. Glaciol., 37(126), 261-269

Bradford JH, Nichols J, Mikesell TD and Harper JT (2009) Continuous profiles of electromagnetic wave velocity and water content in glaciers: an example from Bench Glacier, Alaska, USA. Ann. Glaciol., 50(51), 1-9 (doi: 10.3189/ 172756409789097540)

Colgan W and 6 others (2012) The annual glaciohydrology cycle in the ablation zone of the Greenland ice sheet: Part 2. Observed and modeled ice flow. J. Glaciol., 58(207), 51-64 (doi: 10.3189/ 2012JoG11J081)

Cuffey KM and Paterson WSB (2010) The physics of glaciers, 4th edn. Butterworth-Heinemann, Oxford

De Smedt B, Pattyn F and De Groen P (2010) Using the unstable manifold correction in a Picard iteration to solve the velocity field in higher-order ice-flow models. J. Glaciol., 56(196), 257261 (doi: 10.3189/002214310791968395)

Flowers GE, Björnsson H, Geirsdóttir Á, Miller GH and Clarke GKC (2007) Glacier fluctuation and inferred climatology of Langjökull ice cap through the Little Ice Age Quat. Sci. Rev., 26 (19-21), 2337-2353 (doi: org/10.1016/jquascirev2007.07.016)

Flowers GE, Roux N, Pimentel S and Schoof CG (2011) Present dynamics and future prognosis of a slowly surging glacier. Cryosphere, 5(1), 299-313 (doi: 10.5194/tc-5-299-2011)

Fountain AG and Walder JS (1998) Water flow through temperate glaciers. Rev. Geophys., 36(3), 299-328 (doi: 10.1029/ 97RG03579)

Funk M, Echelmeyer K and Iken A (1994) Mechanisms of fast flow in Jakobshavns Isbræ, West Greenland: Part II. Modeling of englacial temperatures. J. Glaciol., 40(136), 569-585

Gagliardini O, Cohen D, Råback P and Zwinger T (2007) Finiteelement modeling of subglacial cavities and related friction law. J. Geophys. Res., 112(F2), F02027 (doi: 10.1029/2006JF000576)

Gao D (1980) Report on scientific expedition to Mt Qomolangma area (1975) - meteorology and environment. Science Press, Beijing [in Chinese]

Graf WL (1970) The geomorphology of the glacial valley cross section. Arct. Alp. Res., 2(4), 303-312

Greve R and Blatter H (2009) Dynamics of ice sheets and glaciers. Springer, Dordrecht

Harbor JM (1992) Numerical modeling of the development of Ushaped valleys by glacial erosion. Geol. Soc. Am. Bull., 104(10), 1364-1375 (doi: 10.1130/0016-7606(1992)104<1364:NMOT$\mathrm{DO}>2.3 . \mathrm{CO} ; 2)$

Harbor JM (1995) Development of glacial-valley cross sections under conditions of spatially variable resistance to erosion. Geomorphology, 14(2), 99-107 (doi: 10.1016/0169555X(95)00051-1)

Hock R (2003) Temperature index melt modelling in mountain areas. J. Hydrol., 282(1-4), 104-115 (doi: 10.1016/S00221694(03)00257-9)
Hou S and 9 others (2007) Summer temperature trend over the past two millennia using air content in Himalayan ice. Climate Past, 3(1), 89-95 (doi: 10.5194/cp-3-89-2007)

Huang M (1999) Forty years' study of glacier temperature in China. J. Glaciol. Geocryol., 21(3), 193-199 [in Chinese with English summary]

Huss M, Funk M and Ohmura A (2009) Strong Alpine glacier melt in the 1940s due to enhanced solar radiation. Geophys. Res. Lett., 36(23), L23501 (doi: 10.1029/2009GL040789)

Immerzeel WW, Van Beeke LPH and Bierkens MFP (2010) Climate change will affect the Asian water towers. Science, 328(5984), 1382-1385 (doi: 10.1126/science.1183188)

Irvine-Fynn TDL, Moorman BJ, Williams JLM and Walter FSA (2006) Seasonal changes in ground-penetrating radar signature observed at a polythermal glacier, Bylot Island, Canada. Earth Surf. Process. Landf., 31(7), 892-909 (doi: 10.1002/esp.1299)

Kang S, Qin D, Mayewski PA, Wake CP and Ren J (2001) Climatic and environmental records from the Far East Rongbuk ice core, Mt. Qomolangma (Everest). Episodes, 24(3), 176-181

Lanzhou Institute of Glaciology and Geocryology (LIGG) (1988) An introduction to the glaciers in China. Science Press, Beijing [in Chinese]

Liu W (2010) Hydrometeorological characteristics and runoff simulation in the Rongbuk Glacier catchment in Mt. Qomolangma, central Himalayas, China. (PhD thesis, Cold and Arid Regions Environmental and Engineering Research Institute, Chinese Academy of Sciences)

Naito N, Nakawo M, Kadota T and Raymond CF (2000) Numerical simulation of recent shrinkage of Khumbu Glacier, Nepal Himalayas. IAHS Publ. 264 (Symposium at Seattle 2000 Debris-Covered Glaciers), 245-254

Nye JF (1959) The motion of ice sheets and glaciers. J. Glaciol., 3(26), 493-507

Pattyn F (2002) Transient glacier response with a higher-order numerical ice-flow model. J. Glaciol., 48(162), 467-477 (doi: 10.3189/172756502781831278)

Pattyn F (2003) A new three-dimensional higher-order thermomechanical ice-sheet model: basic sensitivity, ice stream development, and ice flow across subglacial lakes. J. Geophys. Res., 108(B8), 2382 (doi: 10.1029/2002JB002329)

Pellicciotti F, Brock BW, Strasser U, Burlando P, Funk $M$ and Corripio JG (2005) An enhanced temperature-index glacier melt model including shortwave radiation balance: development and testing for Haut Glacier d'Arolla, Switzerland. J. Glaciol., 51(175), 573-587 (doi: 10.3189/172756505781829124)

Pimentel S, Flowers GE and Schoof CG (2010) A hydrologically coupled higher-order flowband model of ice dynamics with a Coulomb friction sliding law. J. Geophys. Res., 115(F4), F04023 (doi: 10.1029/2009JF001621)

Schoof C (2005) The effect of cavitation on glacier sliding. Proc. $R$. Soc. London, Ser. A, 461(2055), 609-627 (doi: 10.1098/ rspa.2004.1350)

Svensson H (1959) Is the cross-section of a glacial valley a parabola? J. Glaciol., 3(25), 362-363

Tibetan Scientific Expedition of the Chinese Academy of Sciences (TSECAS) (1975) Monograph on Mount Qomolangma scientific expedition (1966-1968): modern glacier and geomorphology. Science Press, Beijing [in Chinese]

Van der Veen CJ and Whillans IM (1989) Force budget: I. Theory and numerical methods. J. Glaciol., 35(119), 53-60

$\mathrm{Xu} \mathrm{J}$ and 6 others (2009) Records of volcanic events since AD 1800 in the East Rongbuk ice core from Mt. Qomolangma. Chinese Sci. Bull., 54(8), 1411-1416 (doi: 10.1007/sf1434-0090020-y) [in Chinese]

Yang X, Zhang T, Qin D, Kang S and Qin X (2011) Characteristics and changes in air temperature and glacier's response on the north slope of Mt. Qomolangma (Mt. Everest). Arct. Antarct. Alp. Res., 43(1), 147-160 (doi: 10.1657/19384246-43.1.147) 
Ye Q, Zhong Z, Kang S, Stein A, Wei Q and Liu J (2009) Monitoring glacier and supra-glacier lakes from space in Mt. Qomolangma region of the Himalayas on the Tibetan Plateau in China. J. Mt. Sci. [China], 6, 211-220 (doi: 10.1007/s11629-009-1016-4)

Zhang T, Xiao C, Qin X, Hou D and Ding M (2012) Ice thickness observation and landform study of East Rongbuk glacier, Mt.
Qomolangma. J. Glaciol. Geocryol., 34(5), 1059-1066 [in Chinese with English summary]

Zwinger T and Moore JC (2009) Diagnostic and prognostic simulations with a full Stokes model accounting for superimposed ice of Midtre Lovénbreen, Svalbard. Cryosphere, 3(2), 217-229 (doi: 10.5194/tc-3-217-2009)

MS received 28 October 2012 and accepted in revised form 20 January 2013 